\section{BRAZIULIAN JOURNAL \\ OF MEDICAL AND BIOLOGICAL RESEARCH}

www.bjournal.com.br
ISSN 1414-431X

Volume 45 (12) 1102-1340 December 2012

\section{BIOMIDICAL SCIENCES}

AND

CLINICAL INVESTIGATION

Braz J Med Biol Res, December 2012, Volume 45(12) 1240-1243

doi: 10.1590/S0100-879X2012007500153

Participation of cannabinoid receptors in peripheral nociception induced by some NSAIDs

L.C.R. Silva, T.R.L. Romero, L.S. Guzzo and I.D.G. Duarte

The Brazilian Journal of Medical and Biological Research is partially financed by

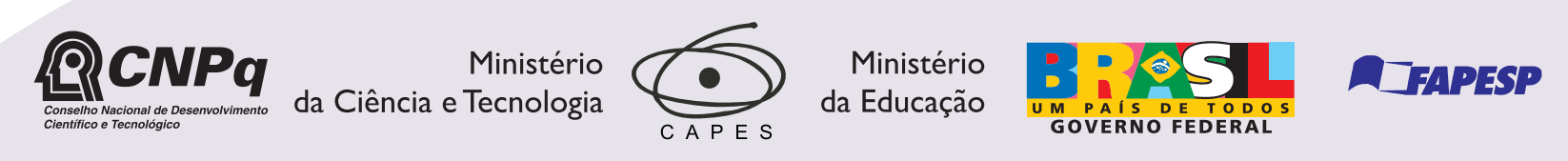

Institutional Sponsors

scie/
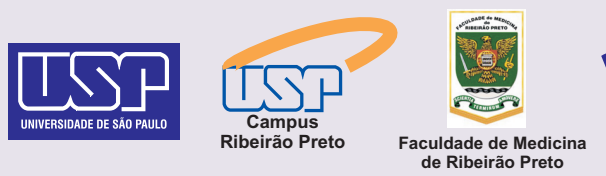

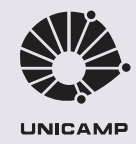

UNICAMP $\oplus$ SHIMADZU

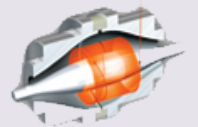

1D Associaçäo Explore High - Performance MS Orbitrap Technology In Proteomics \& Metabolomics analitica $\underset{\text { analiticaweb.com.br }}{\text { Thermo }}$ S I N TIFIC 


\title{
Participation of cannabinoid receptors in peripheral nociception induced by some NSAIDs
}

\author{
L.C.R. Silva, T.R.L. Romero, L.S. Guzzo and I.D.G. Duarte \\ Departamento de Farmacologia, Instituto de Ciências Biológicas, \\ Universidade Federal de Minas Gerais, Belo Horizonte, MG, Brasil
}

\begin{abstract}
Nonsteroidal anti-inflammatory drugs (NSAIDs) have been used extensively to control inflammatory pain. Several peripheral antinociceptive mechanisms have been described, such as opioid system and NO/cGMP/KATP pathway activation. There is evidence that the cannabinoid system can also contribute to the in vivo pharmacological effects of ibuprofen and indomethacin. However, there is no evidence of the involvement of the endocannabinoid system in the peripheral antinociception induced by NSAIDs. Thus, the aim of this study was to investigate the participation of the endocannabinoid system in the peripheral antinociceptive effect of NSAIDs. All experiments were performed on male Wistar rats (160-200 g; $\mathrm{N}=4$ per group). Hyperalgesia was induced by a subcutaneous intraplantar (ip/) injection of prostaglandin $\mathrm{E}_{2}\left(\mathrm{PGE}_{2}, 2 \mu \mathrm{g} / \mathrm{paw}\right)$ in the rat's hindpaw and measured by the paw pressure test $3 \mathrm{~h}$ after injection. The weight in grams required to elicit a nociceptive response, paw flexion, was determined as the nociceptive threshold. The hyperalgesia was calculated as the difference between the measurements made before and after $P G E_{2}$, which induced hyperalgesia (mean $=83.3 \pm 4.505 \mathrm{~g})$. AM-251 $(80 \mu \mathrm{g} / \mathrm{paw})$ and AM-630 $(100 \mu \mathrm{g} / \mathrm{paw})$ were used as $\mathrm{CB}_{1}$ and $\mathrm{CB}_{2}$ cannabinoid receptor antagonists, respectively. Ip/ injection of $40 \mu \mathrm{g}$ dipyrone (mean $=5.825 \pm 2.842 \mathrm{~g}$ ), $20 \mu \mathrm{g}$ diclofenac (mean $=4.825 \pm 3.850 \mathrm{~g}$ ) and $40 \mu \mathrm{g}$ indomethacin (mean $=6.650 \pm 3.611 \mathrm{~g}$ ) elicited a local peripheral antinociceptive effect. This effect was not antagonized by $i p / \mathrm{CB}_{1}$ cannabinoid antagonist to dipyrone (mean $=5.00 \pm 0.9815 \mathrm{~g}$ ), diclofenac (mean $=2.50 \pm 0.8337$ $\mathrm{g}$ ) and indomethacin (mean $=6.650 \pm 4.069 \mathrm{~g}$ ) or $\mathrm{CB}_{2}$ cannabinoid antagonist to dipyrone (mean $=1.050 \pm 6.436 \mathrm{~g}$ ), diclofenac $($ mean $=6.675 \pm 1.368 \mathrm{~g})$ and indomethacin $($ mean $=2.85 \pm 5.01 \mathrm{~g})$. Thus, cannabinoid receptors do not seem to be involved in the peripheral antinociceptive mechanism of the NSAIDs dipyrone, diclofenac and indomethacin.
\end{abstract}

Key words: Nonsteroidal anti-inflammatory drugs (NSAIDs); Peripheral antinociception; Cannabinoid system

\section{Introduction}

Cannabinoids can be broadly defined as compounds with actions on cannabinoid receptors together with chemically related compounds. They include compounds derived from the plant Cannabis sativa with $\Delta^{9}-\mathrm{THC}$ as prototype, the related group of synthetic drugs and finally the endogenous eicosanoids, with anandamide as the compound most extensively studied (1). At the peripheral level, cannabinoid receptors are known to be involved in primary afferent neuron modulation, inhibiting membrane excitation and $\mathrm{Ca}^{2+}$ conductance and also increasing potassium conductance, inducing a similar antinociceptive effect. The antinociceptive effect of the endocannabinoid system has been implicated in pain models (2).

Nonsteroidal anti-inflammatory drugs (NSAIDs) like dipyrone, diclofenac and indomethacin are widely prescribed for their antinociceptive and analgesic activity (3). The search for different mechanisms of NSAID-induced antinociception has greatly increased after investigators observed that inhibi- tion of prostaglandin synthesis in the inflamed tissue is not the only pathway for this response. Previous studies have demonstrated that the opioid system and the NO/cGMP/KATP pathway could be involved in the antinociceptive mechanism of NSAIDs $(4,5)$. There is evidence indicating that the cannabinoid system can contribute to the in vivo pharmacological effects of ibuprofen and indomethacin (6). Gühring et al. (7) have suggested that indomethacin may allow an increased synthesis of endocannabinoids from arachidonic acid by blocking cyclooxygenase (COX). The same investigators have shown that spinal pretreatment with AM-251 blocks the antinociception caused by indomethacin. However, there is no evidence of involvement of the endocannabinoid system in the peripheral antinociception induced by NSAIDs.

Thus, the objective of the present study was to investigate the participation of the $\mathrm{CB}_{1}$ and $\mathrm{CB}_{2}$ cannabinoid receptors in the peripheral antinociceptive effect of the NSAIDs dipyrone, diclofenac and indomethacin.

Correspondence: I.D.G. Duarte, Departamento de Farmacologia, ICB-UFMG, Av. Antônio Carlos, 6627, 31270-100 Belo Horizonte, MG, Brasil. E-mail: dimitri@icb.ufmg.br

Received March 10, 2012. Accepted August 3, 2012. Available online September 21, 2012. Published December 17, 2012. 


\section{Material and Methods}

\section{Animals}

All experiments were performed on male Wistar rats (160-200 g) from CEBIO-UFMG (Universidade Federal de Minas Gerais) housed in a temperature-controlled room (23 $\left.\pm 1^{\circ} \mathrm{C}\right)$ on an automatic 12-h light/dark cycle (6:00-18:00 h). Food and water were freely available until the beginning of the experiments. Animals were used only once and sacrificed after the experiments.

All animal procedures and protocols were approved by the Ethics Committee for Animal Experimentation (CETEA) of the UFMG.

\section{Measurement of hyperalgesia}

Hyperalgesia was induced by a subcutaneous injection of prostaglandin $\mathrm{E}_{2}\left(\mathrm{PGE}_{2} ; 2 \mu \mathrm{g}\right)$ into the plantar surface of the hind paw and measured using the paw pressure test described by Randall and Selitto (8). An analgesimeter was used (Ugo-Basile, Italy) with a cone-shaped paw-presser with a rounded tip, which applies a linearly increasing force to the hind paw. The weight in grams required to elicit the nociceptive response of paw flexion was determined as the nociceptive threshold. A cutoff value of $300 \mathrm{~g}$ was used to reduce the possibility of damage to the paws. The nociceptive threshold was measured in the right paw and determined as the average of three consecutive trials recorded before and $3 \mathrm{~h}$ after $\mathrm{PGE}_{2}$ injection. The hyperalgesia was calculated as the difference between these two averages ( $\Delta$ of nociceptive threshold) and reported in grams.

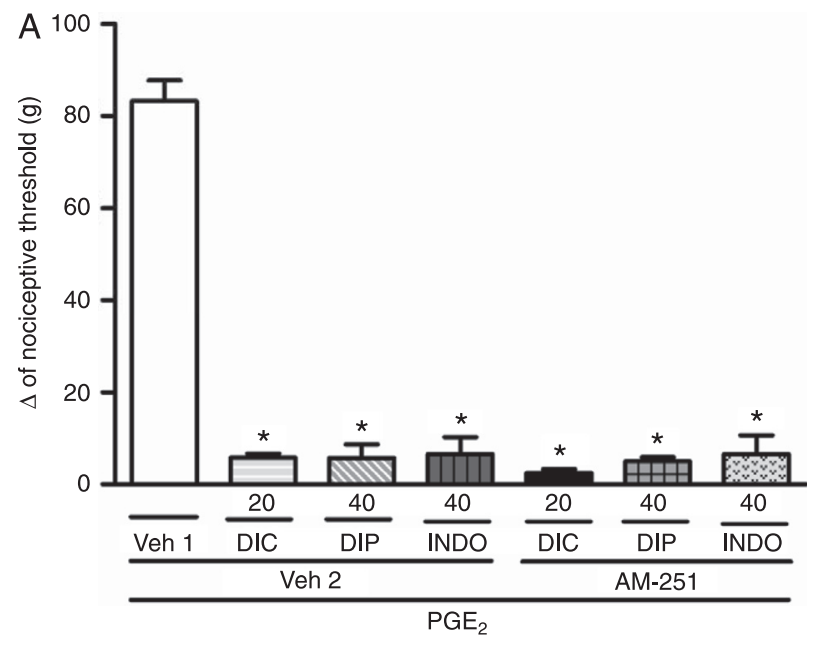

\section{Drug administration}

All drugs were administered by injecting a volume of $50 \mu \mathrm{L} /$ paw, with the exception of $\mathrm{PGE}_{2}(100 \mu \mathrm{L} / \mathrm{paw})$. Diclofenac (Purifarma, Brazil) and dipyrone (Sigma, USA) were dissolved in isotonic saline, while indomethacin (Sigma) was dissolved in Tris-base buffer. The $\mathrm{CB}_{1}$ and $\mathrm{CB}_{2}$ cannabinoid receptor antagonists, AM-251 (Tocris, USA) and AM-630 (Tocris) were dissolved in 10\% DMSO in saline. $\mathrm{PGE}_{2}$ (Cayman, USA) was dissolved in $2 \%$ ethanol in saline.

\section{Experimental protocol}

NSAIDs were injected into the right hind paw 2:55 h after local injection of $\mathrm{PGE}_{2}$. AM-251 and AM-630 were administered $10 \mathrm{~min}$ prior to the NSAIDs. The nociceptive threshold was assessed $3 \mathrm{~h}$ after local administration of $\mathrm{PGE}_{2}$.

\section{Statistical analysis}

Data were analyzed statistically by one-way analysis of variance (ANOVA) and the post hoc Bonferroni test for multiple comparisons. Probabilities of less than $5 \%$ ( $P<$ 0.05 ) were considered to be statistically significant.

\section{Results}

Dipyrone $(40 \mu \mathrm{g})$, diclofenac $(20 \mu \mathrm{g})$ and indomethacin $(40 \mu \mathrm{g})$ injected into the right hind paw produced an antinociceptive response against the hyperalgesia induced by local injection of $\mathrm{PGE}_{2}$ (2 $\mu \mathrm{g} / \mathrm{paw}$; Figure $1 \mathrm{~A}$ and $\left.\mathrm{B}\right)$. The

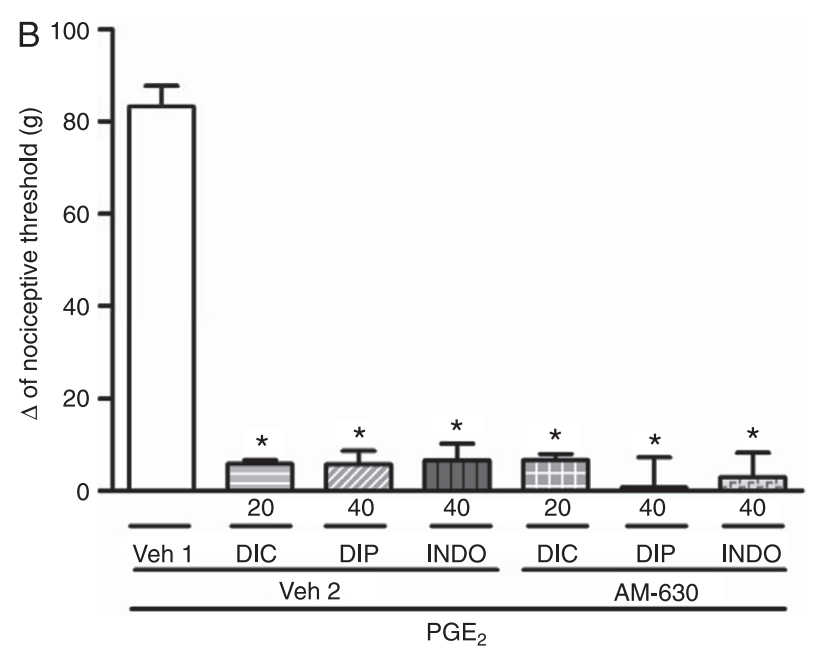

Figure 1. A, Effect induced by intraplantar administration of AM-251 (80 $\mu \mathrm{g} / \mathrm{paw})$ on nonsteroidal antinociceptive drug (NSAID)-induced peripheral antinociception in the hyperalgesic paw [prostaglandin $\mathrm{E}_{2}\left(\mathrm{PGE}_{2}\right) 2 \mu \mathrm{g}$ ]. AM-251 was injected 15 min prior to the NSAIDs diclofenac (DIC, $20 \mu \mathrm{g} / \mathrm{paw}$ ), dipyrone (DIP, $40 \mu \mathrm{g} / \mathrm{paw}$ ) and indomethacin (INDO, $40 \mu \mathrm{g} / \mathrm{paw}$ ), which were administered 2:55 h after local administration of $\mathrm{PGE}_{2}$. Data are reported as means $\pm \mathrm{SEM}$ for $\mathrm{N}=4$ animals. ${ }^{*} \mathrm{P}<0.001$ compared to $\mathrm{PGE}_{2}$ (ANOVA followed by the Bonferroni post-test). Veh $1=$ saline; Veh $2=10 \%$ DMSO. B, Effect of intraplantar administration of AM-630 (100 $\mu \mathrm{g} / \mathrm{paw})$ on NSAID-induced peripheral antinociception in the hyperalgesic paw ( $\left.\mathrm{PGE}_{2}, 2 \mu \mathrm{g}\right)$. AM-630 was injected 15 min prior to the NSAIDs DIC $(20 \mu \mathrm{g} / \mathrm{paw})$, DIP $(40 \mu \mathrm{g} / \mathrm{paw})$ and INDO $(40 \mu \mathrm{g} / \mathrm{paw})$, which were administered 2:55 h after local administration of PGE 2 . Data are reported as means \pm SEM for $N=4$ animals. ${ }^{*} \mathrm{P}<0.001$ compared to $\mathrm{PGE}_{2}$ (ANOVA followed by the Bonferroni post-test). 
antinociceptive effects were not antagonized by the $\mathrm{CB}_{1}$

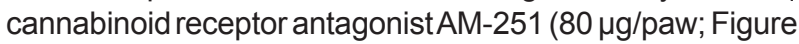
$1 \mathrm{~A}$ ) or by the $\mathrm{CB}_{2}$ cannabinoid receptor antagonist, $\mathrm{AM}-630$ $(100 \mu \mathrm{g} /$ paw; Figure 1B). AM-251 and AM-630 had no effect when each was administered alone (data not shown).

\section{Discussion}

Since the discovery of the G-protein-coupled cannabinoid receptor $(9,10)$ and the identification of anandamide, an endogenous cannabinoid ligand (11), there has been increased interest in the actions of cannabinoids.

To understand the physiological role of endocannabinoids, in-depth knowledge of their actions, biosynthesis and the factors that control it is required. Arachidonoyl ethanolamide (anandamide) is an endogenous ligand for $\mathrm{CB}_{1}$ receptors that was shown to be a metabolite of arachidonic acid. Although it is not clear through which pathway arachidonic acid contributes to the synthesis of endocannabinoids, it was shown that arachidonic acid mobilization increases anandamide synthesis (12).

Endocannabinoids are metabolized by fatty acid amide hydrolase (FAAH), monoacylglycerol lipase (MAGL) (12) and by other enzymes such as COX-2 (13). Thus, the inhibition of spinal COX-2 produces analgesia by inhibiting not only pronociceptive prostaglandins, but also endocannabinoid breakdown (14). A possible interaction between the analgesic activity of COX inhibitors and endocannabinoids was proposed in the behavioral study by Gühring et al. (7). This study showed that pretreatment of the spine with AM251 blocked the indomethacin-induced antinociception of the formalin response or of zymosan-induced hyperalgesia. Moreover, these investigators added further evidence that indomethacin acts at the spinal level at least at three sites. First, it blocks the COXs, an action that results in higher levels of arachidonic acid used for endocannabinoid synthesis. Second, it lowers nitric oxide (NO) production, reducing the breakdown of endocannabinoids. Third, indomethacin inhibits FAAH, contributing to the sparing of endocannabinoid levels (7). On the basis of these interactions between COX inhibitors and the endocannabinoid system the present study assessed the participation of the endocannabinoid system in the peripheral antinociception induced by NSAIDs.

A recent study using the model of knee inflammation in

\section{References}

1. Freund TF, Katona I, Piomelli D. Role of endogenous cannabinoids in synaptic signaling. Physiol Rev 2003; 83: 10171066.

2. Howlett AC, Breivogel CS, Childers SR, Deadwyler SA, Hampson RE, Porrino LJ. Cannabinoid physiology and pharmacology: 30 years of progress. Neuropharmacology rats demonstrated that administration of just COX-2 into the spine, but not COX-1 and non-selective inhibitors, reversed the spinal hyperexcitability. This result might be explained by the prevention of 2-arachidonoyl glycerol (2-AG) breakdown observed only when a selective COX-2 inhibitor was used and this response was prevented or partially reversed by AM-251. Thus, this interaction may depend on the sites of action of different COX inhibitors (14).

Our study showed that dipyrone, diclofenac and indomethacin induced antinociceptive effects. These effects were considered to be peripheral since NSAIDs administered into the right paw did not produce an antinociceptive effect in the left paw (data not shown). Moreover, NSAIDs did not induce antinociception when injected into nonhyperalgesic paws (data not shown). In addition to the classical inhibition of COX $(15,16)$, some studies have indicated that opioids and the NO/cGMP/KATP pathway could be involved in the antinociceptive mechanism of NSAIDs $(5,17)$. Additionally, the literature indicates that the suppression of sodium currents in sensory neurons by diclofenac and flufenamic acid would contribute to their analgesic activity (18). However, this does not seem to be the case in the present study because the doses used were specifically reversed by NO synthase and opioid receptor antagonists (Romero TRL, Duarte IDG, unpublished data).

It has been reported that AM-251 and AM-630, at the same doses and time of administration as used in the present study, were able to significantly decrease the antinociceptive effect of the $\mathrm{CB}_{1}$ and $\mathrm{CB}_{2}$ cannabinoid receptor agonists arachidonyl-2-chloroethylamide and $\mathrm{N}$-palmitoyl-ethanolamine, respectively (data not shown), and the $\mu$-opioid receptor agonist morphine (19). However, the present study demonstrated that AM-251 and AM-630 were not able to decrease the peripheral antinociceptive effect of dipyrone, diclofenac and indomethacin injected into the hind paw of rats.

The present results provide evidence that $\mathrm{CB}_{1}$ and $\mathrm{CB}_{2}$ cannabinoid receptors do not seem to be involved in the peripheral antinociceptive mechanism of the NSAIDs dipyrone, diclofenac and indomethacin.

\section{Acknowledgments}

Research supported by CNPq grants and fellowships.

2004; 47 (Suppl 1): 345-358

3. Patrono C, Rocca B. Nonsteroidal antiinflammatory drugs: past, present and future. Pharmacol Res 2009; 59: 285289.

4. Miranda HF, Pinardi G. Lack of effect of naltrindole on the spinal synergism of morphine and non-steroidal anti- 
inflammatory drugs (NSAIDS). J Physiol Pharmacol 2009; 60: 71-76.

5. Ortiz MI, Granados-Soto V, Castaneda-Hernandez G. The NO-cGMP-K ${ }^{+}$channel pathway participates in the antinociceptive effect of diclofenac, but not of indomethacin. Pharmacol Biochem Behav 2003; 76: 187-195.

6. Holt S, Paylor B, Boldrup L, Alajakku K, Vandevoorde S, Sundstrom A, et al. Inhibition of fatty acid amide hydrolase, a key endocannabinoid metabolizing enzyme, by analogues of ibuprofen and indomethacin. Eur J Pharmacol 2007; 565: 26-36.

7. Gühring $H$, Hamza M, Sergejeva M, Ates M, Kotalla CE, Ledent $C$, et al. A role for endocannabinoids in indomethacininduced spinal antinociception. Eur J Pharmacol 2002; 454: 153-163.

8. Randall LO, Selitto JJ. A method for measurement of analgesic activity on inflamed tissue. Arch Int Pharmacodyn Ther 1957; 111: 409-419.

9. Gerard CM, Mollereau C, Vassart G, Parmentier M. Molecular cloning of a human cannabinoid receptor which is also expressed in testis. Biochem J 1991; 279 (Part 1): 129-134.

10. Matsuda LA, Lolait SJ, Brownstein MJ, Young AC, Bonner TI. Structure of a cannabinoid receptor and functional expression of the cloned cDNA. Nature 1990; 346: 561-564.

11. Devane WA, Hanus L, Breuer A, Pertwee RG, Stevenson LA, Griffin G, et al. Isolation and structure of a brain constituent that binds to the cannabinoid receptor. Science 1992; 258: 1946-1949.

12. Pestonjamasp VK, Burstein SH. Anandamide synthesis is induced by arachidonate mobilizing agonists in cells of the immune system. Biochim Biophys Acta 1998; 1394: 249260.

13. Kozak KR, Prusakiewicz JJ, Marnett LJ. Oxidative metabolism of endocannabinoids by COX-2. Curr Pharm Des 2004; 10: $659-667$

14. Telleria-Diaz A, Schmidt M, Kreusch S, Neubert AK, Schache $F$, Vazquez E, et al. Spinal antinociceptive effects of cyclooxygenase inhibition during inflammation: Involvement of prostaglandins and endocannabinoids. Pain 2010; 148: 26-35.

15. Vane JR. Inhibition of prostaglandin synthesis as a mechanism of action for aspirin-like drugs. Nat New Biol 1971; 231: 232-235.

16. Brogden RN, Heel RC, Pakes GE, Speight TM, Avery GS. Diclofenac sodium: a review of its pharmacological properties and therapeutic use in rheumatic diseases and pain of varying origin. Drugs 1980; 20: 24-48.

17. Miranda HF, Pinardi G. Lack of effect of naltrexone on the spinal synergism between morphine and non steroidal antiinflammatory drugs. Pharmacol Rep 2009; 61: 268-274.

18. Lee HM, Kim HI, Shin YK, Lee CS, Park M, Song JH. Diclofenac inhibition of sodium currents in rat dorsal root ganglion neurons. Brain Res 2003; 992: 120-127.

19. Pacheco DF, Klein A, Perez AC, Pacheco CM, de Francischi $\mathrm{JN}$, Reis GM, et al. Central antinociception induced by muopioid receptor agonist morphine, but not delta- or kappa-, is mediated by cannabinoid CB1 receptor. $\mathrm{Br} \mathrm{J}$ Pharmacol 2009; 158: 225-231. 